\title{
Factors affecting serum phenobarbital concentration changes in pediatric patients receiving elixir and powder formulations
}

\author{
Chihiro Shiraishi', Hiroko Matsuda', Toru Ogura² and Takuya Iwamoto ${ }^{1 *}$ (D)
}

\begin{abstract}
Background: Phenobarbital (PB) is commonly used as elixir and powder formulations in pediatric care. Its dose adjustment is performed based on individual drug concentration monitoring. Few studies have comprehensively analyzed the variation factors for serum PB concentration. In this study, we retrospectively investigated the factors that influence serum PB concentration and assessed the impacts of dosage formulation and administration route.

Methods: This retrospective cohort study covered clinical data from January 2007 to September 2019 at Mie University Hospital. The present study included 60 pediatric patients administered the elixir and powder of PB through oral route and enteral tube. Simple and multiple linear regression analyses were performed to identify the risk factors that affect the weight-corrected PB serum concentration/dose (C/D) ratio in pediatric patients. Six subgroups were also established according to the concomitant use of drugs that potentially inhibit PB metabolism, dosage formulation, and administration route to investigate the difference in the PB C/D ratio among the subgroups.
\end{abstract}

Results: A significant regression equation to predict the PB C/D ratio was found through simple and multiple linear regression analyses, with an adjusted coefficient of determination of $0.53(p<0.001)$. Further, the concomitant uses of valproic acid (VPA) or amiodarone, which were the only two drugs seen in this study as potential inhibitors of $P B$, was found to have the greatest effect on the $P B C / D$ ratio (standardized partial regression coefficient $(\beta)=0.543$, $p<0.001$ ). Furthermore, a significant difference in the PB C/D ratio was found between the subgroups classified by the concomitant use of VPA or amiodarone $(p=0.002)$. However, there were no significant correlations between the PB C/D ratio, dosage formulation, and administration route.

Conclusions: The most influential factor on the PB C/D ratio was the concomitant use of VPA or amiodarone with PB. This result could provide an important perspective in pediatric drug therapy where elixir and powder formulations are administered via the oral route and enteral tube.

Keywords: Phenobarbital, Pediatric care, Elixir, Powder, Serum concentration

\footnotetext{
* Correspondence: taku-iwa@clin.medic.mie-u.ac.jp

'Department of Pharmacy, Mie University Hospital, 2-174 Edobashi, Tsu, Mie 514-8507, Japan

Full list of author information is available at the end of the article
}

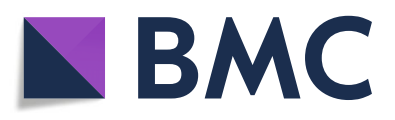

(c) The Author(s). 2021 Open Access This article is licensed under a Creative Commons Attribution 4.0 International License, which permits use, sharing, adaptation, distribution and reproduction in any medium or format, as long as you give appropriate credit to the original author(s) and the source, provide a link to the Creative Commons licence, and indicate if changes were made. The images or other third party material in this article are included in the article's Creative Commons licence, unless indicated otherwise in a credit line to the material. If material is not included in the article's Creative Commons licence and your intended use is not permitted by statutory regulation or exceeds the permitted use, you will need to obtain permission directly from the copyright holder. To view a copy of this licence, visit http://creativecommons.org/licenses/by/4.0/ The Creative Commons Public Domain Dedication waiver (http://creativecommons.org/publicdomain/zero/1.0/) applies to the data made available in this article, unless otherwise stated in a credit line to the data. 


\section{Background}

In 1912, phenobarbital (PB) was developed and released by Hauptmann [1] for the treatment of epileptic seizures $[2,3]$. Presently, it remains one of the first-line drugs for the treatment of suspected neonatal seizures [4]. PB requires drug concentration monitoring to assess compliance, evaluate therapy response and adjust dosage. In pediatric medical care, dosage formulation is often switched between elixir and powder for several reasons, such as nonadherence and easy handling of dose adjustment with growth in pediatric patients. Previous investigations have demonstrated that serum $\mathrm{PB}$ concentration increased after the dosage formulation was switched from powder to elixir without a change in dose. In addition, the weight-corrected serum concentration/dose $(\mathrm{C} / \mathrm{D})$ ratio of $\mathrm{PB}$ in pediatric patients receiving $\mathrm{PB}$ elixir was reported to be significantly higher than that in pediatric patients receiving PB powder [5]. However, few studies have comprehensively analyzed the variation factors for serum $\mathrm{PB}$ concentration, including the dosage formulation and administration route.

In this study, we comprehensively analyzed the factors that affect the changes in serum PB concentrations, including the dosage formulation and administration route, in pediatric patients.

\section{Methods}

\section{Patients}

This retrospective study included data from 79 pediatric patients from January 2007 to September 2019 at Mie University Hospital. Patients meeting the following inclusion criteria were enrolled: (i) received the elixir and powder of $\mathrm{PB}$ (PHENOBAL ${ }^{\bullet} \mathrm{POWDER}^{\mathrm{P}}$
$10 \%$ or ELIXIRS $0.4 \%$, DAIICHI SANKYO Co., Ltd., Tokyo) orally and via an enteral tube, (ii) $0-15$ years of age, and (iii) had one or more serum PB samples. Patient demographic data were obtained via a review of electronic medical records. Patients were excluded if their serum PB concentration was not at a steady state $(n=10)$, which was attained by repeated constant PB dose for more than 10 days based on the elimination half time of 2.5 days in the pediatric population [6]. Patients administered additional PB injections (NOBELBAR ${ }^{\oplus}$, NOBELPHARMA Co., Ltd., Tokyo) $(n=5)$ or PB suppository (WAKOBITAL ${ }^{\oplus}$, TAKATA Pharmaceutical Co., Ltd., Saitama) $(n=2)$ during the study period and those with confirmed medication noncompliance based on the electronic medical records $(n=2)$ were excluded. Patients were defined as full analysis set (FAS) and a flow chart of patient selection was drafted (Fig. 1). Patient demographic data included sex, age, body weight, PB dose, number of daily $\mathrm{PB}$ doses, $\mathrm{PB}$ dose per body weight, serum $\mathrm{PB}$ concentration, dosage formulation, administration route, serum albumin (ALB), aspartate aminotransferase (AST), alanine aminotransferase (ALT), lactase dehydrogenase $(\mathrm{LDH}), \gamma$-glutamyl transpeptidase $(\gamma \mathrm{GTP})$, blood urea nitrogen (BUN), serum creatinine $(\mathrm{Scr})$, and causative disorder. The medication history of drugs that potentially interact with $\mathrm{PB}$, which might affect serum $\mathrm{PB}$ concentration (i.e., amiodarone, fluconazole, miconazole, disulfiram, fluvastatin, fluvoxamine, metronidazole, voriconazole, valproic acid (VPA), and stiripentol) [7, 8], was also assessed.

This study was conducted in accordance with the Declaration of Helsinki and its amendments, and was

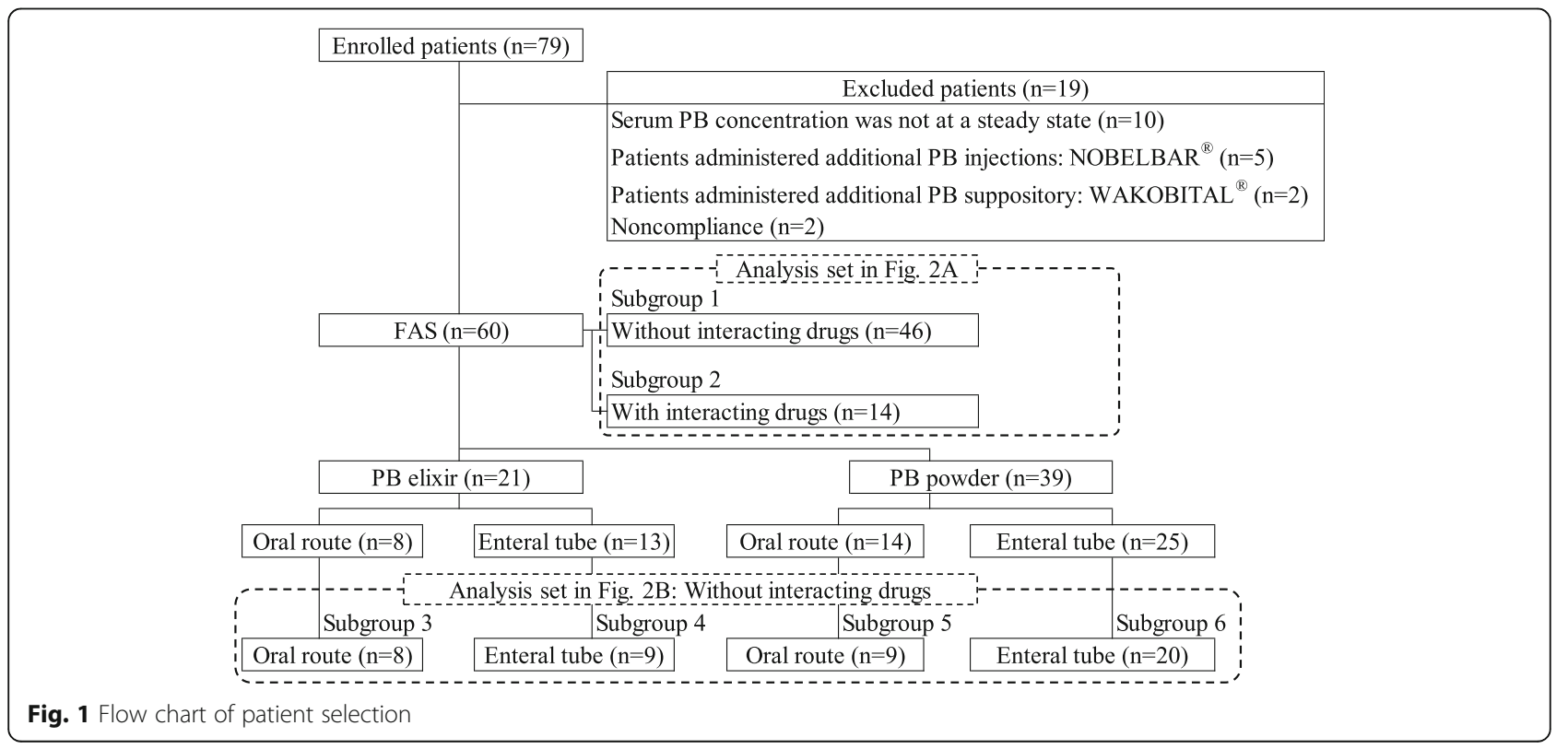


approved by the Clinical Research Ethics Review Committee of Mie University Hospital (No. H2020-026).

\section{Serum PB samples and assay methods}

In each study, serum $\mathrm{PB}$ samples were separated from whole blood by centrifugation at $1700 \times \mathrm{g}$ for $10 \mathrm{~min}$ at $19-26^{\circ} \mathrm{C}$ using serum separation tube, and the total $\mathrm{PB}$ concentration was measured immediately. Total serum PB concentrations were determined using a chemiluminescent immunoassay reagent and a TDx ${ }^{\oplus}$ FLx (Abbott Diagnostics, Chicago, IL, U.S.A.) from 2007 to 2013 and ARCHITECT $^{\circledast}$ i1000SR (Abbott Laboratories, Chicago, IL) from 2014 to 2019. The quantitative range of PB for both instruments was $1.1-80 \mu \mathrm{g} / \mathrm{mL}$.

\section{Patient subgroups}

As indicated in Fig. 1, the following 6 subgroups were established to evaluate the causes of the serum PB concentration changes, including the concomitant use of a drug that potentially interacts with $\mathrm{PB}$ (subgroups 1 and $2)$, dosage formulation, and administration route (subgroups 3-6). Subgroup $1(n=46)$ had patients without interacting drugs while subgroup $2(n=14)$ had patients with interacting drugs. Patients in subgroups $3,4,5$, and 6 did not take the interacting drugs. Other characteristics of each subgroup were: subgroups $3(n=8)$ and 4 $(n=9)$ had patients receiving PB elixir via oral route and enteral tube, respectively, and subgroups $5(\mathrm{n}=9)$ and 6 $(n=20)$ had patients receiving PB powder via oral route and enteral tube, respectively.

\section{Statistical analyses}

Statistical analyses were performed using IBM SPSS Statistics version 25.0 (IBM, Ltd., Tokyo). Categorical and continuous variables on patient background were summarized as median [first quartile-third quartile] and frequency (percentage), respectively. Simple linear regression analysis was conducted to investigate the variation factors of the weight-corrected $\mathrm{PB} C / \mathrm{D}$ ratio, and standardized partial regression coefficient was calculated.

Multiple linear regression analysis using the forward stepwise selection method and the optimal multiple regression equation was conducted for the significant factors related to the weight-corrected $\mathrm{PB} C / \mathrm{D}$ ratio observed in the simple linear regression analysis. In this analysis, sex was coded as $1=$ male 2 =female, formulation was $1=\mathrm{PB}$ elixir $2=\mathrm{PB}$ powder, interacting drug use was $1=$ no 2 =yes, and administration route was $1=$ oral route 2 = enteral tube, respectively.

For the subgroup analyses, the data are presented as mean \pm standard deviation and were analyzed using Student's t-test or one-way analysis of variance (ANOVA).
A $p$-value of $<0.05$ was considered to indicate statistical significance.

\section{Results \\ Patients}

Based on the inclusion and exclusion criteria, 60 patients were enrolled in the retrospective study as FAS (Fig. 1). During the study period, the elixir and powder of $\mathrm{PB}$ were administered to 21 and 39 patients, respectively. All serum PB concentrations of the study subjects were within the calibration curve range. The patient characteristics are summarized in Table 1. The median [first quartile-third quartile] age and body weight of the study patients were $1.0(0.6-2.5)$ years and $8.2(4.7-11.7) \mathrm{kg}$, respectively. The median daily $\mathrm{PB}$ dose, number of daily PB doses, and amount of PB dose per body weight were 40.0 (20.0-60.0) mg/day, 2.0 (2.0-2.0) times/day, and 2.6 (1.9-3.7) $\mathrm{mg} / \mathrm{kg} / \mathrm{time}$, respectively. The median serum concentration of PB was $16.0(11.2-25.0) \mu \mathrm{g} / \mathrm{mL}$. For the concomitant use of drugs that potentially interact with $\mathrm{PB}$, the number of patients receiving VPA and amiodarone was $13(22 \%)$ and $1(2 \%)$, respectively. No other drugs were not identified as the interacting drugs of $\mathrm{PB}$ including typical CYP inducers in this study.

\section{Simple linear regression analysis}

Simple linear regression analysis was performed using the weight-corrected $\mathrm{PB} C / \mathrm{D}$ ratio as the dependent variable and patient background as the explanatory variable. Table 2 shows the results of standardized partial regression coefficient $(\beta), 95 \%$ confidence interval $(\mathrm{CI})$, and $p$-value of a test on standardized partial regression coefficient. The significant variables were age $(\beta=0.390$, $p=0.002)$, interacting drug use $(\beta=0.516, p<0.001)$, body weight $(\beta=0.443, p<0.001)$, and LDH $(\beta=0.259$, $p=0.045)$. As shown in Fig. 2a, a significant difference in the $\mathrm{PB} C / \mathrm{D}$ ratio was observed between subgroups 1 and 2 , which were classified by interacting drug use ( $p=$ 0.002). There were no significant correlations between the $\mathrm{PB} C / \mathrm{D}$ ratio and the other factors investigated.

\section{Multiple linear regression analysis}

Table 3 shows the results of the regression equation by multiple linear regression analysis (forward stepwise selection method). The explanatory variables were selected according to a significant correlation with the weightcorrected $\mathrm{PB} C / \mathrm{D}$ ratio by single linear regression analysis. This analysis revealed that the factors for the $\mathrm{PB}$ $\mathrm{C} / \mathrm{D}$ ratio in pediatric patients were interacting drug use (standardized partial regression coefficient [ $\beta], 0.543$, $p<0.001)$, body weight $(\beta=0.346, \mathrm{p}<0.001)$, and LDH $(\beta=0.272, p=0.006)$. The following significant regression equation was found to predict the $\mathrm{PB} C / \mathrm{D}$ ratio, (an adjusted coefficient of determination $=0.530, \mathrm{p}<0.001$ ): 
Table 1 Baseline characteristics of the patients

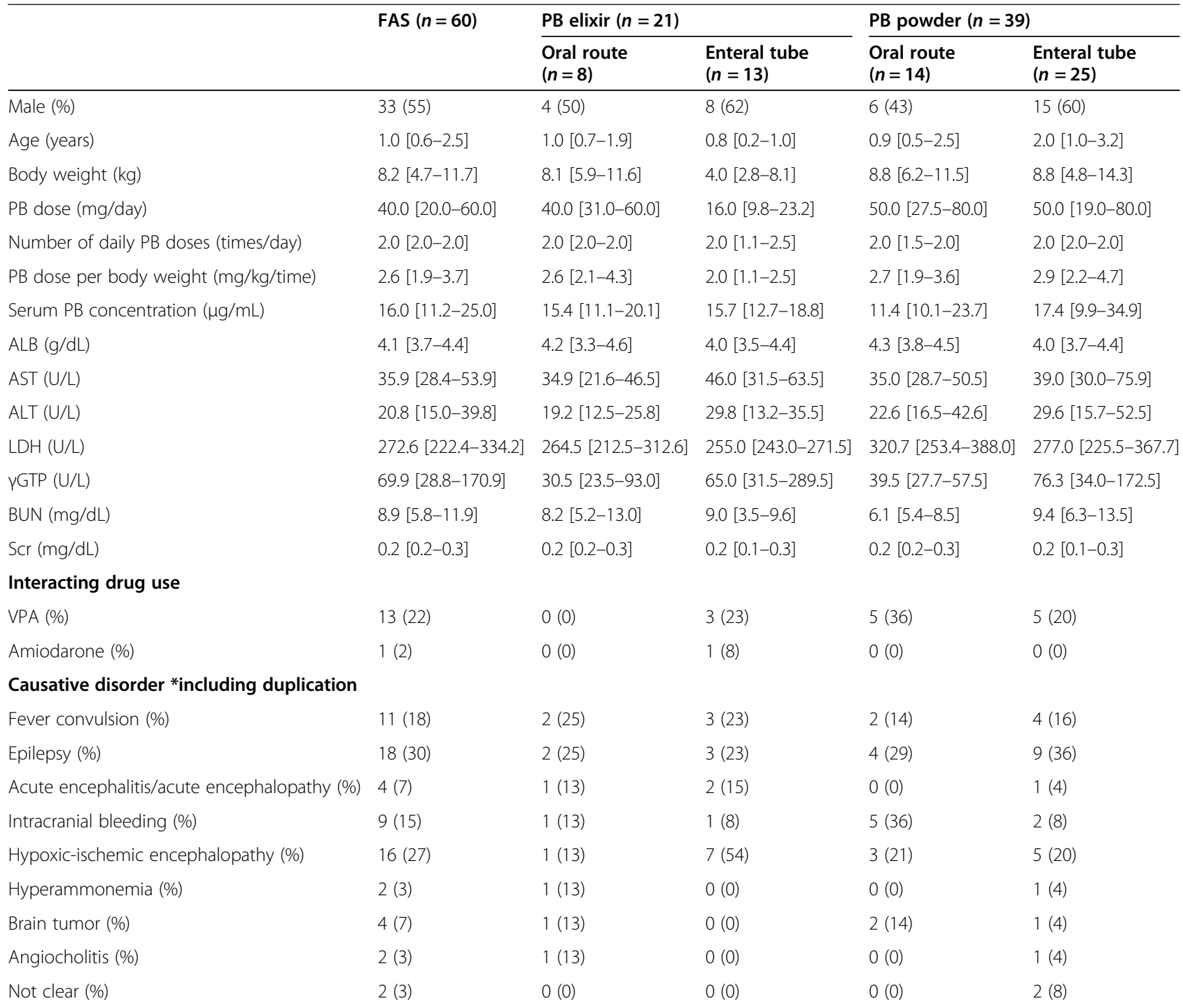

Data are shown as frequency (percentage) or median [first quartile-third quartile]

PB phenobarbital, FAS full analysis set, ALB serum albumin, AST aspartate aminotransferase, ALT alanine aminotransferase, LDH lactate dehydrogenase, $\gamma$ GTP $\gamma-$ glutamyl transpeptidase, BUN blood urea nitrogen, $\mathrm{Scr}$ serum creatinine, VPA valproic acid

Weight-corrected $\mathrm{PB} \quad \mathrm{C} / \mathrm{D} \quad$ ratio $=-2.026+$ $2.961 \times$ [interacting drug use: $(1=$ no, $2=$ yes $)]+$ $0.185 \times$ [body weight $(\mathrm{kg})]+0.004 \times[\mathrm{LDH}(\mathrm{U} / \mathrm{L})]$.

The concomitant use of the potential interacting drugs against $\mathrm{PB}$ had the largest effect on the prediction equation of the weight-corrected $\mathrm{PB} C / \mathrm{D}$ ratio. In contrast, the subgroup analysis classified by the administration route and dosage formulation (subgroups 3-6) showed no significant differences based on the weight-corrected $\mathrm{PB}$ C/D ratio (Fig. 2b).

\section{Discussion}

A simple linearity is reported to be observed between serum $\mathrm{PB}$ concentration and dose in the concentration range of $10-40 \mu \mathrm{g} / \mathrm{mL}$ [9]. Further, the bioavailability of the elixir and powder of $\mathrm{PB}$ is almost $100 \%$ [10]. However, this finding was observed with adult data. Over the neonatal and infant periods, the bioavailability of $\mathrm{PB}$ is estimated to be less than $50 \%$, and the systemic clearance of $\mathrm{PB}$ follows a sigmoidal pattern [11]. Age-related drug disposition changes derived from liver and kidney function, plasma protein binding rate, tissue distribution volume, and metabolic enzyme activity contribute to the pharmacokinetic differences in the pediatric population [12-15]. Gastric $\mathrm{pH}$ is also increased in the pediatric population and reaches adult $\mathrm{pH}$ values by 2 years of age. PB is a weak acid product and its absorption rate in pediatric population is lower than that in older children and adult [16]. Since intestinal 
Table 2 Simple linear regression analysis for the weight-corrected PB C/D ratio

\begin{tabular}{llll}
\hline & $\boldsymbol{\beta}$ & $\mathbf{9 5 \%} \mathbf{C l}$ & $\mathbf{p}$-value \\
\hline Male & 0.094 & $-0.168-0.355$ & 0.477 \\
Age & 0.390 & $0.147-0.632$ & 0.002 \\
Body weight & 0.443 & $0.207-0.679$ & $<0.001$ \\
PB dose & 0.163 & $-0.097-0.422$ & 0.214 \\
Number of daily PB doses & 0.116 & $-0.145-0.377$ & 0.376 \\
ALB & 0.133 & $-0.128-0.393$ & 0.312 \\
AST & 0.151 & $-0.109-0.411$ & 0.249 \\
ALT & -0.135 & $-0.395-0.125$ & 0.304 \\
LDH & 0.259 & $0.006-0.513$ & 0.045 \\
YGTP & 0.249 & $-0.005-0.504$ & 0.055 \\
BUN & -0.037 & $-0.300-0.226$ & 0.779 \\
Scr & 0.037 & $-0.226-0.300$ & 0.780 \\
Interacting drug use (VPA or amiodarone) & 0.516 & $0.291-0.741$ & $<0.001$ \\
Dosage formulation & -0.225 & $-0.481-0.032$ & 0.085 \\
Administration route & -0.134 & $-0.395-0.126$ & 0.306 \\
\hline
\end{tabular}

C/D serum concentration/dose, VPA valproic acid, PB phenobarbital, ALB serum albumin, AST aspartate aminotransferase, ALT alanine aminotransferase, LDH lactate dehydrogenase, $\gamma$ GTP $\gamma$-glutamyl transpeptidase, BUN blood urea nitrogen, Scr serum creatinine $\beta$ standardized partial regression coefficient, $\mathrm{Cl}$ confidence interval

Simple linear regression analysis was performed using the weight-corrected PB C/D ratio as the dependent variable and patient background as the explanatory variable

motility depends on feeding habits, drug administration that elevate gastric $\mathrm{pH}$, and intestinal bacterial growth [16, 17], concomitant use of proton-pump inhibitors (PPI) or histamine type $2\left(\mathrm{H}_{2}\right)$ receptor antagonists may cause the decreased intestinal absorption of $\mathrm{PB}$ in pediatric patients. In this study, there were only 2 patients who concomitantly received PPI or $\mathrm{H}_{2}$ receptor antagonists during the study period. Indeed, the weight-corrected $\mathrm{PB} C / \mathrm{D}$ ratios $[3.48$ and $3.05(\mu \mathrm{g} / \mathrm{ml}) /(\mathrm{mg} / \mathrm{kg})]$ in the two patients were relatively lower than the mean \pm standard deviation value $[4.05 \pm 0.30(\mu \mathrm{g} / \mathrm{ml}) /(\mathrm{mg} / \mathrm{kg})]$ in the patients without PPI or $\mathrm{H}_{2}$ receptor antagonists. The bioavailability of phenytoin and ganciclovir, both of which are weak acid drugs, was also reported to be lower in the pediatric population than in adults [18, 19]. Additional analysis is needed to reveal the contribution of gastric $\mathrm{pH}$ to the intestinal absorption of PB.

Several causes of serum PB concentration fluctuations, including dosage formulation, have been reported. To our knowledge, our study is the first to comprehensively analyze the variation factors of serum PB concentration with drug-drug interactions, dosage formulation, and administration route. We demonstrated that the concomitant use of the drugs that potentially interact with $\mathrm{PB}$ significantly affected the $\mathrm{PB} C / \mathrm{D}$ ratio in pediatric patients. $\mathrm{PB}$ is partly metabolized in the liver at $45-65 \%$ mainly by CYP $2 \mathrm{C} 9$, which matures significantly within 1 year of age $[8,20]$. In addition, the main metabolite is further conjugated with gluconic acid [20]. For instance, the unbound oral clearance of (S)-warfarin, a typical substrate of CYP2C9, in the pediatric population was reported to be significantly lower than that in adults [21]. Immature CYP2C9 activity in neonates may affect the pharmacokinetic differences in its substrates between neonates and adult patients. On the other hand, clearance of PB has been reported to be higher in children than in adults [22]. Similarly, in our study, simple linear regression analysis showed a positive correlation between $\mathrm{PB} C / \mathrm{D}$ ratio and age. These evidences provide the insight that drug interaction between $\mathrm{PB}$ and its inhibitors should be predicted under the consideration of patient's age.

VPA inhibits N-glucoside excretion, which contributes $16.2 \%$ of PB metabolism [23]. Further, the serum PB concentration in patients with VPA was reported to be $32 \%$ higher than that in patients without VPA [23]. In our study, one of the 14 patients who received drugs that might interact with $\mathrm{PB}$ was also administered amiodarone, and his weight-corrected C/D ratio of 4.2 was relatively higher than that in the patients without interacting drugs (mean weight-corrected C/D ratio: 3.79). For amiodarone, desethylamiodarone (DEA), a principal metabolite of amiodarone, inhibits CYP1A1, CYP1A2, CYP2A6, CYP2B6, CYP2C9, CYP2C19, CYP2D6, and CYP3A4 [24]. DEA has been reported to potently inhibit CYP2C9-mediated warfarin hydroxylation both in vitro and in vivo [25]. Although there have been no reports demonstrating the elevation of serum $\mathrm{PB}$ concentration 

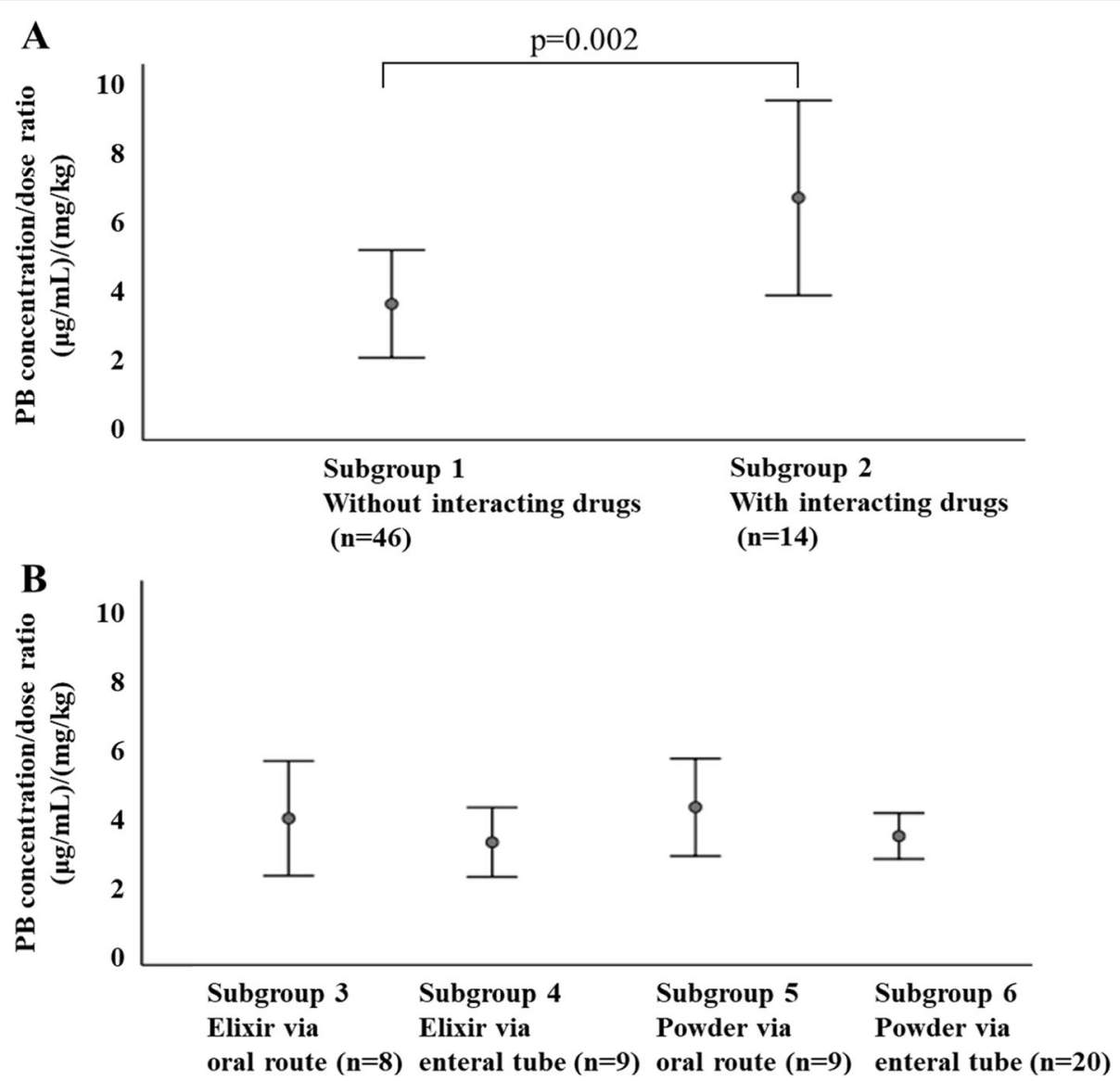

Fig. 2 Difference in the weight-corrected PB C/D ratio between groups. (A) Effect of the concomitant use of the interacting drugs (VPA or amiodarone), (B) Effect of administration route and dosage formulation

due to the concomitant use of amiodarone, the AUC of (S)-warfarin administered concomitantly with amiodarone increased to $211 \%$ compared to that of (S)-warfarin alone [25].

In the present study, multiple linear regression analysis showed that body weight and LDH were risk factors that

Table 3 Multiple linear regression analysis for the weightcorrected PB C/D ratio

\begin{tabular}{llllll}
\hline & $\mathbf{a}$ & $\boldsymbol{\beta}$ & $\mathbf{9 5 \%} \mathbf{C l}$ & $\mathbf{p}$-value & VIF \\
\hline Constant & -2.026 & & & & \\
Body weight & 0.185 & 0.346 & $0.139-0.533$ & $<0.001$ & 1.039 \\
LDH & 0.004 & 0.272 & $0.086-0.478$ & 0.006 & 1.037 \\
Interacting drug use & 2.961 & 0.543 & $0.306-0.700$ & $<0.001$ & 1.042 \\
(VPA or amiodarone) & & & & &
\end{tabular}

C/D serum concentration/dose, VPA valproic acid, PB phenobarbital, LDH lactate dehydrogenase, a partial regression coefficient, $\beta$ standardized partial regression coefficient, $\mathrm{Cl}$ confidence interval, VIF variance inflation factor Multiple linear regression analysis (forward stepwise selection method) and regression equation was found.

The explanatory variables were selected according to a significant correlation with the weight-corrected PB C/D ratio using single linear regression analysis. Weight-corrected PB C/D ratio $=-2.026+2.961 \times$ [interacting drug use: $(1=$ no, $2=$ yes $)]+0.185 \times[$ body weight $(\mathrm{kg})]+0.004 \times[\mathrm{LDH}(\mathrm{U} / \mathrm{L})]$ affected the $\mathrm{PB} \mathrm{C} / \mathrm{D}$ ratio (Table 3 ). In neonates, extracellular fluid accounts for $40-50 \%$ of body weight, which is quite higher than that in adults (30\%) [26]. In addition, the reported protein binding rate of $\mathrm{PB}$ in newborns less than 2 weeks (37\%) is lower than that in adults (51\%) [27]. Such changes are partly related to the differences of the volume of distribution of $\mathrm{PB}$ between pediatric and adult patients (pediatric patient: $0.9 \mathrm{~L} / \mathrm{kg}$ [28] vs. adult: $0.7 \mathrm{~L} / \mathrm{kg}$ [29]). Therefore, a decrease in the proportion of water composition and $\mathrm{PB}$ tissue distribution with growth during childhood might be associated with an increase in the weight-corrected C/D ratio of PB. However, more evidence will be needed to clarify the contribution of the water composition to the $\mathrm{C} / \mathrm{D}$ ratio of PB. LDH is an enzyme present in almost all body tissues. Elevated LDH is often observed in liver disease, anemia, heart attack, bone fractures, muscle trauma, cancers, and infections [30]. Since AST and ALT were not extracted as risk factors by simple and multiple linear regression analyses in our study, liver dysfunction might not affect the increase in the $\mathrm{PB} C / \mathrm{D}$ ratio. $\mathrm{Al}$ though the influence of $\mathrm{LDH}$ on the $\mathrm{PB} C / \mathrm{D}$ ratio was 
less than the existence of drug-drug interactions, further research is needed to confirm the relationship between LDH level and serum PB concentration.

In this study, we found no relationship between the PB C/D ratio and dosage formulation (elixir vs. powder) in contrast to the previous report [5]. The previous report showed that there were significant differences in the weight-corrected $\mathrm{PB} C / \mathrm{D}$ ratio between the elixir and powder groups $[5.7 \pm 2.6$ vs. $3.6 \pm 2.1(\mu \mathrm{g} / \mathrm{ml}) /(\mathrm{mg} /$ $\mathrm{kg})(p=0.044)]$. Our study is quite similar to the previous study in point of the number of patients, age, and ethics. However, analysis and evaluation methods differ from each other. In addition, the difference of PB formulation between powder and elixir was a focal point in the previous report and the concomitant use of drugs, the difference of administration route, and liver and kidney functions were not included as confounding factors. Since our study performed a multivariate analysis with pediatric care issues, including drug-drug interactions, more reliable data were considered to be provided.

Because dosage formulation with easy dose adjustment is desirable for the pediatric population, liquid and powder formulations are commonly selected as suitable formulations for use in pediatric medical care. As shown in Fig. 2b, the dosage formulation and administration route did not largely affect the serum PB concentration when VPA or amiodarone was not administered concomitantly. In the present study, 4 patients switched from the elixir to the powder PB formulation and had serum PB concentration before and after switching. In a patient concomitantly using VPA, the $\mathrm{PB} C / \mathrm{D}$ ratio decreased by 2.33 after the PB formulation was switched (C/D ratio: elixir 9.09, powder 6.76); this was the largest change among the 4 patients. Meanwhile, the absolute values of the differences in the $\mathrm{PB} C / \mathrm{D}$ ratio in the other 3 patients without VPA or amiodarone were 1.30, 0.95, 0.57, respectively. This result demonstrates the importance of considering drug-drug interactions against $\mathrm{PB}$ in pediatric drug therapy.

This study had some limitations. First, we could not evaluate the data by age because of the limited number of patients. As a result, a large variability in the absolute value of the weight-corrected C/D ratio (Fig. 2a, b) was observed. Therefore, a more age-specific survey would be required. Additionally, only 14 patients used drugs that might affect their serum PB concentration.

This study is a retrospective chart review, and prospective studies are needed to determine the importance of drug-drug interactions in $\mathrm{PB}$ administration to pediatric patients.

\section{Conclusion}

Herein, the concomitant use of VPA or amiodarone was found to largely affect the $\mathrm{PB} C / \mathrm{D}$ ratio in pediatric patients. However, switching from the elixir to the powder $\mathrm{PB}$ formulation and administration route did not have a significant effect on the $\mathrm{PB} C / \mathrm{D}$ ratio. Our study can be viewed as a valuable attempt in the evaluation of clinical data of pediatric patients. Further, our results could provide important perspectives in pediatric drug therapy where elixir and powder formulations are administered via the oral route and an enteral tube.

\section{Abbreviations \\ PB: phenobarbital; C/D: serum concentration/dose; FAS: full analysis set; ALB: serum albumin; AST: aspartate aminotransferase; ALT: alanine aminotransferase; LDH: lactase dehydrogenase; $\gamma$ GTP: $\gamma$-glutamyl transpeptidase; Scr: serum creatinine; BUN: blood urea nitrogen; ANOVA: analysis of variance; VPA: valproic acid; $\beta$ : standardized partial regression coefficient; $\mathrm{Cl}$ : confidence interval}

\section{Acknowledgments}

We would like to thank Editage (www.editage.jp) for English language editing.

\section{Authors' contributions}

All authors contributed to the study conception and design. HM conceived the study. CS was involved in data collection. CS, TO and TI were involved in date analysis and interpretation and drafting of the manuscript. TO and TI critically revised the manuscript. All authors have read and approved the final manuscript.

\section{Funding}

Not applicable.

\section{Availability of data and materials}

All data generated or analyzed during this study are included in this published article.

\section{Ethics approval and consent to participate}

This study was conducted in accordance with the Declaration of Helsinki and was approved by the Ethics Committee of the Clinical Research Ethics Review Committee of Mie University Hospital (No. H2020-026). Informed consent was obtained via optout through the website.

Consent for publication

Not applicable.

Competing interests

All authors declare that they have no competing interests.

\section{Author details}

'Department of Pharmacy, Mie University Hospital, 2-174 Edobashi, Tsu, Mie 514-8507, Japan. ${ }^{2}$ Clinical Research Support Center, Mie University Hospital, Tsu, Japan.

Received: 10 November 2020 Accepted: 13 January 2021 Published online: 02 February 2021

\section{References}

1. Hauptmann A. Luminal bei epilepsie. Munch Med Wochenschr. 1912;59: 1907-9

2. Vento M, de Vries LS, Alberola A, Blennow M, Steggerda S, Greisen G, et al. Approach to seizures in the neonatal period: a European perspective. Acta Paediatr. 2010;99:497-501.

3. Sankar JM, Agarwal R, Deorari AK, Paul VK. Management of neonatal seizures. Indian J Pediatr. 2010;77:1129-35.

4. Hellström-Westas L, Boylan G, Agren J. Systematic review of neonatal seizure management strategies provides guidance on anti-epileptic treatment. Acta Paediatr. 2015;104:123-9.

5. Tokiwa C, Nakajima M. The high blood concentration of phenobarbital after a change to elixir from powder. The Japanese Journal of Developmental Pharmacology and Therapeutics. 2018;31:50-3. 
6. Garrettson LK, Dayton PG. Disappearance of phenobarbital and diphenylhydantoin from serum of children. Clin Pharmacol Ther. 1970;11: 674-9.

7. Johannessen SI, Landmark CJ. Antiepileptic drug interactions-principles and clinical implications. Curr Neuropharmacol. 2010;8:254-67.

8. Polasek TM, Lin FP, Miners JO, Doogue MP. Perpetrators of pharmacokinetic drug-drug interactions arising from altered cytochrome p450 activity: a criteria-based assessment. Br J Clin Pharmacol. 2011;71: 727-36.

9. Patsalos PN, Berry DJ, Bourgeois BF, Cloyd JC, Glauser TA, Johannessen SI, et al. Antiepileptic drugs--best practice guidelines for therapeutic drug monitoring: a position paper by the subcommission on therapeutic drug monitoring, ILAE commission on therapeutic strategies. Epilepsia. 2008;49: 1239-76.

10. Meyer MC, Straughn AB, Raghow G, Schary WL, Rotenberg KS. Absorption of phenobarbital from tablets and elixir. J Pharm Sci. 1984 73:485-8.

11. Moffett BS, Weingarten MM, Galati M, Placencia JL, Rodman EA, Riviello J, et al. Phenobarbital population pharmacokinetics across the pediatric age spectrum. Epilepsia. 2018;59:1327-33.

12. Johnson TN, Rostami-Hodjegan A. Resurgence in the use of physiologically based pharmacokinetic models in pediatric clinical pharmacology: parallel shift in incorporating the knowledge of biological elements and increased applicability to drug development and clinical practice. Paediatr Anaesth. 2011:21:291-301.

13. Lu H, Rosenbaum S. Developmental pharmacokinetics in pediatric populations. J Pediatr Pharmacol Ther. 2014;19:262-76.

14. Ehrnebo M, Agurell S, Jalling B, Boréus LO. Age differences in drug binding by plasma proteins: studies on human foetuses, neonates and adults. Eur J Clin Pharmacol. 1971:3:189-93.

15. Strolin-Benedetti M, Baltes EL. Drug metabolism and disposition in children. Fundam Clin Pharmacol. 2003;17:281-99.

16. Heimann G. Enteral absorption and bioavailability in children in relation to age. Eur J Clin Pharmacol. 1980;18:43-50.

17. Weber WW, Cohen SN. Aging effects and drugs in man. In: Gillette JR, Mitchell JR, editors. Concepts in biochemical pharmacology. New York: Academic; 1975. p. 213-33.

18. Frenkel LM, Capparelli EV, Dankner WM, Xu J, Smith IL, Ballow A, et al. Oral ganciclovir in children: pharmacokinetics, safety, tolerance, and antiviral effects. The pediatric AIDS clinical trials group. J Infect Dis. 2000;182:161624.

19. Treluyer JM, Gueret G, Cheron G, Sonnier M, Cresteil T. Developmental expression of CYP2C and CYP2C-dependent activities in the human liver: in-vivo/in-vitro correlation and inducibility. Pharmacogenetics. 1997;7:441-52.

20. Bernus I, Dickinson RG, Hooper WD, Eadie MJ. Inhibition of phenobarbitone N-glucosidation by valproate. Br J Clin Pharmacol. 1994 38:411-6.

21. Takahashi H, Ishikawa S, Nomoto S, Nishigaki Y, Ando F, Kashima T, et al. Developmental changes in pharmacokinetics and pharmacodynamics of warfarin enantiomers in Japanese children. Clin Pharmacol Ther. 2000;68: 541-55

22. Yukawa E, Higuchi S, Aoyama T. The effects of age and concurrently administered of antiepileptic drugs on the apparent clearance of phenobarbital in epileptic children. Yakugaku Zasshi. 1998;108:1081-6.

23. Goto S, Seo T, Murata T, Nakada N, Ueda N, Ishitsu T, et al. Population estimation of the effects of cytochrome p450 2C9 and 2C19 polymorphisms on phenobarbital clearance in Japanese. Ther Drug Monit. 2007;29:118-21.

24. Ohyama K, Nakajima M, Suzuki M, Shimada N, Yamazaki H, Yokoi T. Inhibitory effects of amiodarone and its $\mathrm{N}$-deethylated metabolite on human cytochrome p450 activities: prediction of in vivo drug interactions. Br J Clin Pharmacol. 2000:49:244-53.

25. O'Reilly RA, Trager WF, Rettie AE, Goulart DA. Interaction of amiodarone with racemic warfarin and its separated enantiomorphs in humans. Clin Pharmacol Ther. 1987;42:290-4.

26. Coran AG, Drongowski RA. Body fluid compartment changes following neonatal surgery. J Pediatr Surg. 1989;24:829-32.

27. Murphy JE. Clinical pharmacokinetics fifth edition. In: Battaglia D, Fogle B, editors. ASHP. Bethesda: Academic; 2011. p. 265.
28. Touw DJ, Graafland O, Cranendonk A, Vermeulen RJ, van Weissenbruch MM Clinical pharmacokinetics of phenobarbital in neonates. Eur J Pharm Sci. 2000;12:111-6.

29. Hvidberg EF, Dam M. Clinical pharmacokinetics of anticonvulsants. Clin Pharmacokinet. 1976;1:161-88.

30. Farhana A, Lappin SL. Biochemistry, lactate dehydrogenase. StatPearls.2020. https://www.ncbi.nlm.nih.gov/books/NBK557536/. .

\section{Publisher's Note}

Springer Nature remains neutral with regard to jurisdictional claims in published maps and institutional affiliations.
Ready to submit your research? Choose BMC and benefit from:

- fast, convenient online submission

- thorough peer review by experienced researchers in your field

- rapid publication on acceptance

- support for research data, including large and complex data types

- gold Open Access which fosters wider collaboration and increased citations

- maximum visibility for your research: over $100 \mathrm{M}$ website views per year

At $\mathrm{BMC}$, research is always in progress.

Learn more biomedcentral.com/submissions 